Research Article

\title{
Theoretical Study on the Mechanism for the Formation of Nitro Compounds in Red Oil
}

\author{
Meng-Ke Tian, ${ }^{1}$ Shuang-Ling Tang $\mathbb{D}^{1},{ }^{1}$ Hong-Bin Tang $\mathbb{D}^{2},{ }^{2}$ and Xue-Hai Ju ${ }^{1}$ \\ ${ }^{1}$ School of Environmental and Biochemical Engineering, School of Chemical Engineering, \\ Nanjing University of Science and Technology, Nanjing 210094, China \\ ${ }^{2}$ China Institute of Atomic Energy, P.O. Box 275 (26), Beijing 102413, China \\ Correspondence should be addressed to Shuang-Ling Tang; tshling@163.com and Hong-Bin Tang; thb77@tom.com
}

Received 1 July 2020; Revised 28 August 2020; Accepted 27 September 2020; Published 12 November 2020

Academic Editor: José M. G. Martinho

Copyright (c) 2020 Meng-Ke Tian et al. This is an open access article distributed under the Creative Commons Attribution License, which permits unrestricted use, distribution, and reproduction in any medium, provided the original work is properly cited.

\begin{abstract}
The mechanisms involved in reactions between methane, $n$-hexane, $n$-butanol, cyclohexane, and nitric acid were explored by density functional theory calculations. All the calculations in gas phase and $n$-tributyl phosphate (TBP) solvent were performed at the B3LYP/6-311++G** and CCSD(T)/6-311++G** levels of theory. The results showed that TBP has an important effect on the reactions between nitric acid and alkanes or butanol. The reactions were considered as that the radicals $\left(\cdot \mathrm{NO}_{2}\right.$ and $\cdot \mathrm{NO}_{3} \mathrm{radicals}$ are formed via the $\mathrm{HNO}_{3}$ decomposition under irradiation) initiate the $\mathrm{H}$-atom depletion of the reactants $(\mathbf{R})$, and the produced radicals in red oil combine with $\cdot \mathrm{NO}_{2}$ radical to form the nitro compounds spontaneously. The rate constants of reactions $\mathbf{R}+\cdot \mathrm{NO}_{2}$ and $\mathbf{R}+\cdot \mathrm{NO}_{3}$ differ substantially, the rate constants of the latter being much larger than those of the former. In the reactions of $\mathbf{R}+\cdot \mathrm{NO}_{3}$, the transition states and products are $20 \mathrm{~kJ} / \mathrm{mol}$ and $100 \mathrm{~kJ} / \mathrm{mol}$ or more stable than the reactants, respectively, but the reactions of $\mathbf{R}+\cdot \mathrm{NO}_{2}$ need to overcome energy barriers over $25 \mathrm{~kJ} / \mathrm{mol}$. The formations of products mainly depend on the reactions of $\mathbf{R}+\cdot \mathrm{NO}_{3}$. For the same type of alkanes (either chain or cyclic ones), the lower the relative stabilities of carbon-centered radicals are, the more reactive the alkanes are. Cyclohexane is the most competitive species, followed by $n$ butanol, $n$-alkanes, and methane which are the least competitive.
\end{abstract}

\section{Introduction}

The uranium fuel assembly unloaded from the nuclear reactor is called spent fuel. Some organic solvents like ntributyl phosphate (TBP) and diluents, such as paraffin and cyclohexane, are used to recycle uranium from the spent fuel by the application of the Plutonium Uranium Extraction process [1-6]. The so-called "red oil" was found following several accidents occurring when organic materials inadvertently get into the equipment and overheat with uranyl nitrate and/or nitric acid at uranium processing facilities. However, only some organic compounds can react with uranyl nitrate and/or nitric acid, forming the red oil $[3,7-10]$. Since more accidents have happened due to the formation and violent decomposition of red oil $[4,8-10]$, there was a dawning realization that the formation and decomposition of red oil have become a risk. The safety problem of red oil appealed researchers' attention, and more researchers worldwide started to carry out investigations with the hope of realizing the safe operating conditions.

At present, many investigations have been performed to discuss the formation and decomposition of red oil experimentally. In some accidents, the thermal decomposition of TBP was considered of triggering the thermal release reactions in the nuclear fuel reprocessing plant $[3,9]$. And in some other accidents, the cause of the intense exothermic process was thought to be the oxidation of nitric acid in red oil $[1,3,9-11]$. Therefore, researchers studied the degradation of TBP or the thermal reaction between TBP and nitric acid. Smitha et al. reported the reaction of TBP with nitric acid at different acid concentrations [12-15]; the influences of diluents on the reactions and the behaviors of heat emission were also studied previously [5, 16-23]. Nazin et al. reported thermal explosions in mixtures of TBP with 
nitric acid $[14,24]$. And Gordon et al. studied the decomposition of red oil by simulating these accidents conditions experimentally $[1,7]$. Kumar et al. also reported the thermal decomposition of red oil with nitric acid [25]. Some works were also performed under radiations [26-28].

However, there are majority of investigations concerned with red oil experimentally, which only focus on the degradation of TBP or $\mathrm{TBP} / \mathrm{HNO}_{3}$ system, as well as the factors that influence these reactions. The nitrogen-containing organic materials are the most undesirable waste tank components in the "red oil" accidents, since they are energetic species in their own right $[3,7]$. However, there are limited investigations about them. Therefore, we performed quantum chemical computations to study the formation of nitro compounds when methane $\left(\mathrm{CH}_{4}\right), n$-hexane $\left(n-\mathrm{C}_{6} \mathrm{H}_{14}\right), n$ butanol $\left(n-\mathrm{C}_{4} \mathrm{H}_{9} \mathrm{OH}\right)$, and cyclohexane $\left(c-\mathrm{C}_{6} \mathrm{H}_{12}\right)$ are mixed with nitric acid $\left(\mathrm{HNO}_{3}\right)$ in TBP as solvent. The whole reactions taking place among these components are as the following:

$$
\begin{aligned}
\mathrm{CH}_{4}+\mathrm{HNO}_{3} \longrightarrow & \mathrm{CH}_{3} \mathrm{NO}_{2}+\mathrm{H}_{2} \mathrm{O} \\
n-\mathrm{C}_{6} \mathrm{H}_{14}+\mathrm{HNO}_{3} \longrightarrow & \mathrm{CH}_{3}\left(\mathrm{CH}_{2}\right)_{5} \mathrm{NO}_{2}+\mathrm{H}_{2} \mathrm{O} \\
n-\mathrm{C}_{6} \mathrm{H}_{14}+\mathrm{HNO}_{3} \longrightarrow & \mathrm{CH}_{3} \mathrm{CH}\left(\mathrm{NO}_{2}\right)\left(\mathrm{CH}_{2}\right)_{3} \mathrm{CH}_{3} \\
& +\mathrm{H}_{2} \mathrm{O} \\
n-\mathrm{C}_{6} \mathrm{H}_{14}+\mathrm{HNO}_{3} \longrightarrow & \mathrm{CH}_{3} \mathrm{CH}_{2} \mathrm{CH}\left(\mathrm{NO}_{2}\right)\left(\mathrm{CH}_{2}\right)_{2} \mathrm{CH}_{3} \\
& +\mathrm{H}_{2} \mathrm{O}
\end{aligned}
$$

$$
\begin{array}{r}
n-\mathrm{C}_{4} \mathrm{H}_{9} \mathrm{OH}+\mathrm{HNO}_{3} \longrightarrow n-\mathrm{C}_{4} \mathrm{H}_{9} \mathrm{ONO}_{2}+\mathrm{H}_{2} \mathrm{O} \\
c-\mathrm{C}_{6} \mathrm{H}_{12}+\mathrm{HNO}_{3} \longrightarrow c-\mathrm{C}_{6} \mathrm{H}_{11} \mathrm{NO}_{2}+\mathrm{H}_{2} \mathrm{O}
\end{array}
$$

The reaction mechanisms of these reactions are discussed in the following sections, and we hope to forecast the feasible reactions in the red oil system consisting of more complex components and to provide guidance for the safety problem.

\section{Computational Methods}

All of the geometrical structures including reactants, transition states, and products involved in red oil were optimized at the B3LYP/6-311++G** level of theory. It has been proved that the B3LYP method can provide relative accurate geometries for both inorganic and organic systems [29, 30]. To verify the correct connections among the transition states, corresponding reactants, and products, the intrinsic reaction coordinates (IRC) were determined at the same level. In order to get more accurate relative energies, single point energies (SPE) of reactants, transition states, and products were calculated at the $\operatorname{CCSD}(\mathrm{T}) / 6-311+\mathrm{G}^{* *}$ level based on the optimized geometries at the B3LYP/6-311++G** level. The single point energies were used for the discussions unless otherwise stated. All the calculations were performed with the Gaussian 09 set of programs.

The rate constants of all the pathways were obtained by using the Eyring expression:

$$
k=\frac{k_{\mathrm{B}} T}{h}\left(\frac{P^{0}}{R T}\right)^{1-n} e^{\left(\Delta S^{\ddagger} / R-\Delta H^{\ddagger} / R T\right)} .
$$

in which $k_{\mathrm{B}}$ refers to the Boltzmann constant of $1.38064 \times 10^{-23} \mathrm{~J} \cdot \mathrm{K}^{-1}, h$ refers to the Planck constant of $6.6260696 \times 10^{-34} \mathrm{~J} \cdot \mathrm{s}, T$ is the temperature, $n$ is the sum of computation coefficient for all reactants, $P^{0}$ is the pressure of $1.0 \times 10^{5} \mathrm{~Pa}, R$ is molar gas constant of $8.314 \mathrm{~J} \cdot \mathrm{mol}^{-1} \cdot \mathrm{K}^{-1}$, and $\Delta S^{\neq}$and $\Delta H^{\neq}$are the entropy differences and enthalpy differences between the transition states and corresponding reactants, respectively.

\section{Results and Discussion}

Observing the reactions (1) to (4) listed above, it is easily found that the nitro compounds are produced through the nitro-substitution. However, alkanes or butanol cannot react with nitric acids directly, so an active species is needed to trigger the $\mathrm{C}-\mathrm{H}$ bond cleavage and then react with nitric acids. It was pointed out above that the red oil system is under $\gamma$-ray irradiation. Therefore, it was associated that $\mathrm{HNO}_{3}$ can decompose into nitrogen dioxide radical $\left(\cdot \mathrm{NO}_{2}\right)$ and nitrogen trioxide radical $\left(\cdot \mathrm{NO}_{3}\right)$ under irradiation, which initiate the subsequent reactions. Thus the reactions are divided into three steps. In the following sections, we only discussed the results obtained in the gas phase unless explicitly stated.

3.1. Formation of Nitrogen Dioxide Radical $\left(\mathrm{NO}_{2}\right)$ and $\mathrm{Ni}$ trogen Trioxide Radical $\left(\cdot \mathrm{NO}_{3}\right)$. As depicted in Figure 1, where $\mathbf{R}, \mathbf{P}$, and TS denote the reactant, product, and the transition state, respectively, Path $n$ represents the reaction pathway, and the initial step is the generation of $\cdot \mathrm{NO}_{2}$ and $\cdot \mathrm{NO}_{3}$ radicals. There are three possible generation pathways: (i) the rupture of $\mathrm{N}-\mathrm{O}(\mathrm{H})$ bond of $\mathrm{HNO}_{3}$ leads to $\cdot \mathrm{OH}$ and $\cdot \mathrm{NO}_{2}$ radicals (Path 1 ); then the $\mathrm{OH}$ radical reacts with $\mathrm{HNO}_{3}$ leading to $\mathrm{H}_{2} \mathrm{O}$ and $\mathrm{NO}_{3}$ radical (Path 12a) or $\mathrm{H}_{2} \mathrm{O}_{2}$ and $\cdot \mathrm{NO}_{2}$ radical (Path $12 \mathrm{~b}$ ); (ii) the protonated $\mathrm{HNO}_{3}$, after dehydration, reacts with $\mathrm{NO}_{3}{ }^{-}$ion leading to the $\cdot \mathrm{NO}_{2}$ and $\cdot \mathrm{NO}_{3}$ radicals (Path 2, Path 13); (iii) the dehydration reaction between $\mathrm{HNO}_{3}$ molecules and leads to $\cdot \mathrm{NO}_{2}$ and $\cdot \mathrm{NO}_{3}$ radicals and $\mathrm{H}_{2} \mathrm{O}$ molecule (Path 3, Path 13). Clearly, all the pathways to form radicals occur via bond cleavage under $\gamma$-ray irradiation. It should be pointed out that $\mathrm{HNO}_{3}$ is ionized into $\mathrm{H}^{+}$and $\mathrm{NO}_{3}{ }^{-}$ions in the red oil system, which result in $\mathrm{HNO}_{3}$ molecule protonation firstly, and then protonated $\mathrm{HNO}_{3}$ reacts with $\mathrm{NO}_{3}{ }^{-}$ion via Path 2 and Path 13. Besides, we failed to obtain the transition state of $\mathrm{N}_{2} \mathrm{O} \cdots \mathrm{NO}_{2}$, but it is well known that $\mathrm{N}_{2} \mathrm{O}_{5}$ is a highly reactive species, so its dissociation energy at the B3LYP/ $6-311++G^{* *}$ level is used for the following discussions.

For the present red oil system, the structures of transition states are depicted in Figure 2. The activation free energies of transition states TS1, TS12a, TS12b, TS2, and 


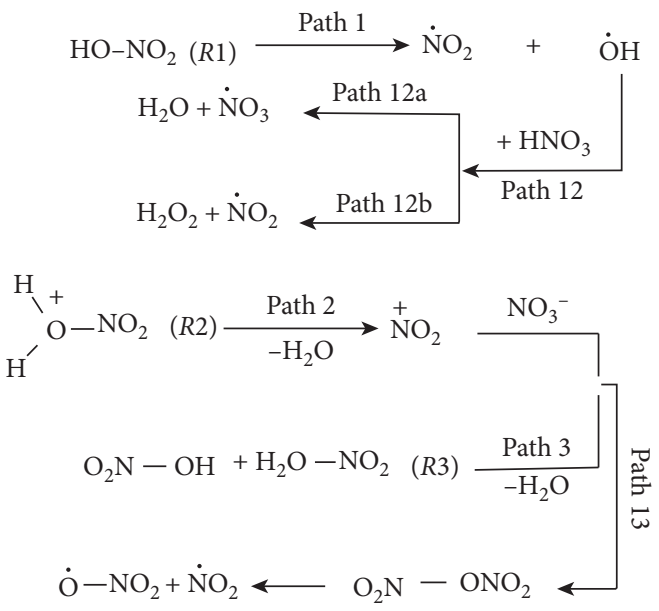

FIgURE 1: Generation of radicals in the dissociation of $\mathrm{HNO}_{3}$.

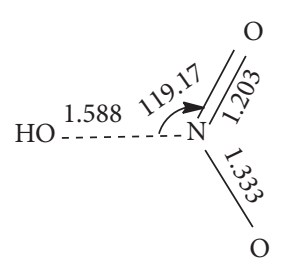

(a)

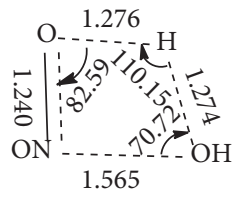

(b)

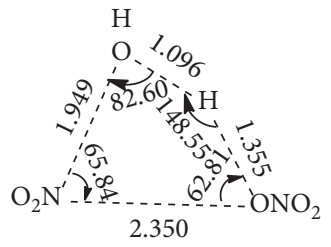

(c)

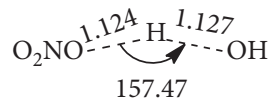
157.47

(d)

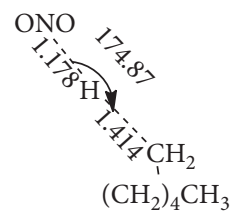

(h)

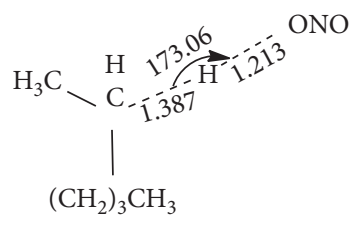

(i)

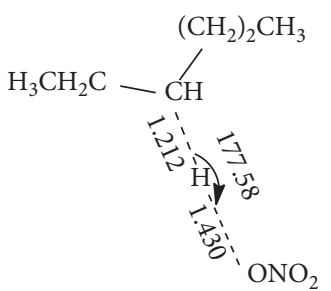

(m)
$\mathrm{ONO}=\overbrace{1.145}^{175.97}-\mathrm{CH}_{3}$

(f) (g)

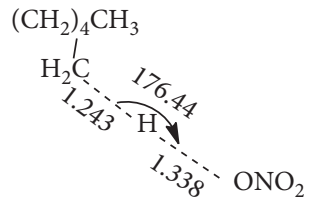

(k)

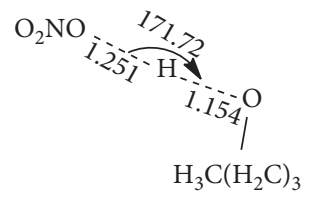

(o)<smiles>CC(CCl)CC1CCCC1C(C)CCl</smiles>

(1)<smiles>COCCONc1ccccc1OC</smiles>

(n)

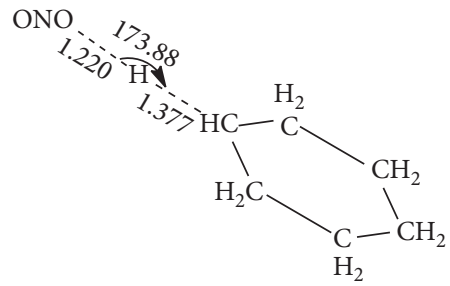

(p)

Figure 2: Optimized structures of transition states at the B3LYP/6-311++ $\mathrm{G}^{* *}$ level in gas phase. Bond lengths are in Angstroms and angles in degrees. The optimized geometrical structures in TBP solvent are similar. (a) TS1. (b) TS2. (c) TS3. (d) TS12a. (e) TS12b. (f) TS4. (g) TS5. (h) TS6a. (i) TS6b. (j) TS6c. (k) TS7a. (l) TS7b. (m) TS7c. (n) TS8. (o) TS9. (p) TS10.

TS3 are $284.03 \mathrm{~kJ} / \mathrm{mol}, \quad 29.94 \mathrm{~kJ} / \mathrm{mol}, \quad 104.51 \mathrm{~kJ} / \mathrm{mol}$, $239.21 \mathrm{~kJ} / \mathrm{mol}$, and $166.78 \mathrm{~kJ} / \mathrm{mol}$, respectively. Though the activation energies are high, they can be overcome easily under $\gamma$-ray irradiation. The energies of the products are $190.32 \mathrm{~kJ} / \mathrm{mol}, 84.95 \mathrm{~kJ} / \mathrm{mol}$, and $35.17 \mathrm{~kJ} / \mathrm{mol}$ higher than corresponding reactants for Path 1, Path 2, and Path 3, 
respectively. Surely, Path $3 \longrightarrow$ Path 12 is the most feasible pathway, forming the $\cdot \mathrm{NO}_{2}$ or $\cdot \mathrm{NO}_{3}$ radicals. The results can be understood from transition states listed in Figure 2 (TS1, TS2, and TS3). The original N-O bond changes from $1.416 \AA$ in $\mathrm{HNO}_{3}$ to $1.588 \AA$ in TS1 and $1.565 \AA$ in TS2, while the $\mathrm{N}$-O bond is $1.949 \AA$ in TS3. The N-O bond lengths indicate the N-O bond interaction is weak in TS3, but the interactions are strong in TS1 and TS2, while the O-H bond interaction in TS3 (1.355 $\AA$ ) is slightly weaker than that of TS2 (O-H bonds lengths are 1.276 $\AA$ and 1.274 $\AA$ ). Therefore, it is easier for TS3 to form radicals.

3.2. Attacks of Radicals to Alkanes or Butanol. The second step (Figure 3 ) is the attack of $\cdot \mathrm{NO}_{2}$ or $\cdot \mathrm{NO}_{3}$ radical on the alkanes or butanol, which leads to direct intermolecular $\mathrm{H}$-shift from carbon or oxygen atom to $\cdot \mathrm{NO}_{2}$ or $\cdot \mathrm{NO}_{3}$ radical. All of the reactions can be written as follows:

$$
\mathbf{R}+\frac{\mathrm{NO}_{2}}{\mathrm{NO}_{3}} \longrightarrow \mathbf{R}+\frac{\mathrm{HNO}_{2}}{\mathrm{HNO}_{3}}
$$

where $\mathbf{R}$ represents reactants (alkanes or butanol). When the $\cdot \mathrm{NO}_{2}$ radical attacks the hydrogen atom of $\mathrm{OH}$ or $\mathrm{CH}$, the isomer products cis-HONO, trans-HONO, and $\mathrm{HNO}_{2}$ can be formed. The activation energies of the reactions $\mathbf{R}+\cdot \mathrm{NO}_{2}$ are listed in Table 1 , in which the symbols $a, b$, and $c$ mean the products $\mathrm{HNO}_{2}$ in different geometrical structures, respectively. The reaction pathways $b$ and $c$ are more competitive than Path a. Meanwhile, Path $b$ plays a slightly more important role than Path $c$. Though the activation energies of these three pathways differ greatly, the reaction mechanisms are similar. There is only the oxygen atom acting as an attacking atom in the $\cdot \mathrm{NO}_{3}$ radical. From the viewpoints expressed above, we mainly discussed the reactions of $\cdot \mathrm{NO}_{2}$ radical in Path $b$ or $\cdot \mathrm{NO}_{3}$ radical reacting with alkanes or butanol.

The reaction mechanisms between $\cdot \mathrm{NO}_{2}$ radical and alkanes or butanol can be described as follows. The reactions of $\mathbf{R}+\cdot \mathrm{NO}_{2}$ occur via the formation of van der Waals complexes firstly. $\cdot \mathrm{NO}_{2}$ radical attaches to $\mathrm{H}$-atom of alkanes or butanol via hydrogen bond interaction in these van der Waals complexes. Then, $\mathrm{H}$-atom transfers from alkanes or butanol to $\cdot \mathrm{NO}_{2}$ radical through the transition states TSn leading to other van der Waals complexes. In these van der Waals complexes, there is a hydrogen bond interaction between $\mathrm{HNO}_{2}$ molecule and the alkane or butanol radical. At last, the $\mathrm{HNO}_{2}$ molecule and alkane or butanol radical formed via the van der Waals' force weaken. The reaction mechanisms of $\mathbf{R}+\cdot \mathrm{NO}_{3}$ are a bit different from those of reactions $\mathbf{R}+\cdot \mathrm{NO}_{2}$. The $\cdot \mathrm{NO}_{3}$ radical attacks $\mathrm{H}$-atom of alkanes or butanol leading to transition states TSn directly, then producing $\mathrm{HNO}_{3}$ and a radical.

The geometrical structures of transition states (TS4 TS10) are shown in Figure 2 and the activation energies, enthalpies, and free energies $\left(\Delta E^{\neq}, \Delta H^{\neq}\right.$and $\left.\Delta G^{\neq}\right)$ of these transition states are listed in Table 2. However, we failed to get the transition state of reaction $c-\mathrm{C}_{6} \mathrm{H}_{12}+\cdot \mathrm{NO}_{3}$ at B3LYP/6-311++G** level. Thus, the transition state of $c-$
$\mathrm{C}_{6} \mathrm{H}_{11} \cdots \mathrm{H} \cdots \mathrm{O}_{3}$ is not listed here. It is found that the relative energies of reactions $\mathrm{R}+\cdot \mathrm{NO}_{2}$ are higher than those of reactions $\mathrm{R}+\cdot \mathrm{NO}_{3}$, which can be explained by the changes of $\mathrm{C}-\mathrm{H}$ or $\mathrm{O}-\mathrm{H}$ bond lengths in transition states. The $\mathrm{O}-\mathrm{H}$ bond lengths in transition states $\mathbf{R N O}_{2}$ are shorter than those in transition states $\mathbf{R N O}_{3}$. On the contrary, the $\mathrm{H}-\mathrm{C}$ bond lengths in transition states $\mathbf{R N O}_{2}$ are longer than those in transition states $\mathbf{R N O}_{3}$.

3.3. Formation of Nitro Compounds. These radicals formed from the above steps combine with each other and form nitro compounds spontaneously (Figure 4, where the symbol $\mathrm{L}$ means the last reaction between radicals to generate the nitro product). For the reactions $n-\mathrm{C}_{6} \mathrm{H}_{14}+\mathrm{HNO}_{3}$, it has the isomer products $\mathrm{CH}_{3}\left(\mathrm{CH}_{2}\right)_{5} \mathrm{NO}_{2}, \quad \mathrm{CH}_{3} \mathrm{CH}\left(\mathrm{NO}_{2}\right)$ $\left(\mathrm{CH}_{2}\right)_{3} \mathrm{CH}_{3}$, and $\mathrm{CH}_{3} \mathrm{CH}_{2} \mathrm{CH}\left(\mathrm{NO}_{2}\right)\left(\mathrm{CH}_{2}\right)_{2} \mathrm{CH}_{3}$.

Single point energies in the gas phase (Table 3 ) calculated at the CCSD (T)/6-311++G** level show that the products of these reactions are $129.2 \mathrm{~kJ} / \mathrm{mol}, 145.3 \mathrm{~kJ} / \mathrm{mol}, 154.5 \mathrm{~kJ} / \mathrm{mol}$, $153.6 \mathrm{~kJ} / \mathrm{mol}, 238.70 \mathrm{~kJ} / \mathrm{mol}$, and $17.2 \mathrm{~kJ} / \mathrm{mol}$ more stable than corresponding reactants, respectively, for reactions (1) to $(4)$.

3.4. Energies along the Reaction Pathways and Rate Constants. According to the discussions above, the differences among the mechanisms of reactions $\mathrm{R}+\cdot \mathrm{NO}_{2} / \cdot \mathrm{NO}_{3}$ are the second step. We mainly discussed the energies and rate constants in the second step in this section. Figure 5 provides the single point energies along the reaction pathways, where the symbols $\mathbf{M}_{\mathbf{i}} \mathbf{n}$ and $\mathbf{M}_{\mathbf{l}} \mathbf{n}$ represent van der Waals complexes, and the energies of reactants are set to zero for reference. As seen from these figures, the products of reactions $\mathrm{R}+\cdot \mathrm{NO}_{3}$ are more stable than the corresponding reactants, and the stability of the products in the reactions $\mathrm{R}+\cdot \mathrm{NO}_{3}$ is in the order $\mathbf{P 9}>\mathbf{P 7 b}>\mathbf{P 7}$ c $>\mathbf{P} 7 \mathrm{a}>\mathbf{P} 5$. However, the energy barriers of transition states $\mathrm{RNO}_{3}$ are less than $-15 \mathrm{~kJ} / \mathrm{mol}$. The energies of products in reactions $\mathrm{R}+\cdot \mathrm{NO}_{2}$ are higher than those of corresponding reactants, except for reaction $c$ $\mathrm{C}_{6} \mathrm{H}_{12}+\cdot \mathrm{NO}_{2}$. The energy barriers of the products increase as follows: P8 (27.24), P6b (38.54), P6c (38.87), P6a (47.93), and $\mathbf{P 4}$ (57.70). Meanwhile, the energy barriers of transition states $\mathbf{R N O}_{2}$ are over $100 \mathrm{~kJ} / \mathrm{mol}$, which are difficult to overcome at room temperature, expect for TS10 $(22.92 \mathrm{~kJ} /$ mol). Therefore, the reactions $\mathrm{R}+\cdot \mathrm{NO}_{3}$ are more competitive than reactions $\mathbf{R}+\cdot \mathrm{NO}_{2}$ and all the reactions $\mathbf{R}+\cdot \mathrm{NO}_{3}$ are kinetically feasible.

The rate constants $(\mathbf{K})$ of the reactions to form transition states at $298 \mathrm{~K}$ are listed in Table 4 . It shows that TBP contributes to the reactions. The rate constants of the dissociation of $\mathrm{N}_{2} \mathrm{O}_{5}$ are $1.14 \times 10^{10} \mathrm{~K} \mathrm{~s}^{-1}$ and $5.38 \times 10^{9} \mathrm{~K} \mathrm{~s}^{-1}$ in gas phase and TBP solvent, respectively. Surely, $\mathrm{N}_{2} \mathrm{O}_{5}$ can decompose easily at room temperature. The rate constants of the reactions to form transition states from $300 \mathrm{~K}$ to $500 \mathrm{~K}$ are shown in Figure 6. There is a linear relationship between $\ln (\mathbf{K})$ and 1/T. As can be seen in Figure 6(a), though the rate constant of TS 1 or TS2 increases more than that of TS3 with increasing temperature, the rate constants of TS3 are higher than the others at the temperature from $300 \mathrm{~K}$ to $500 \mathrm{~K}$. 

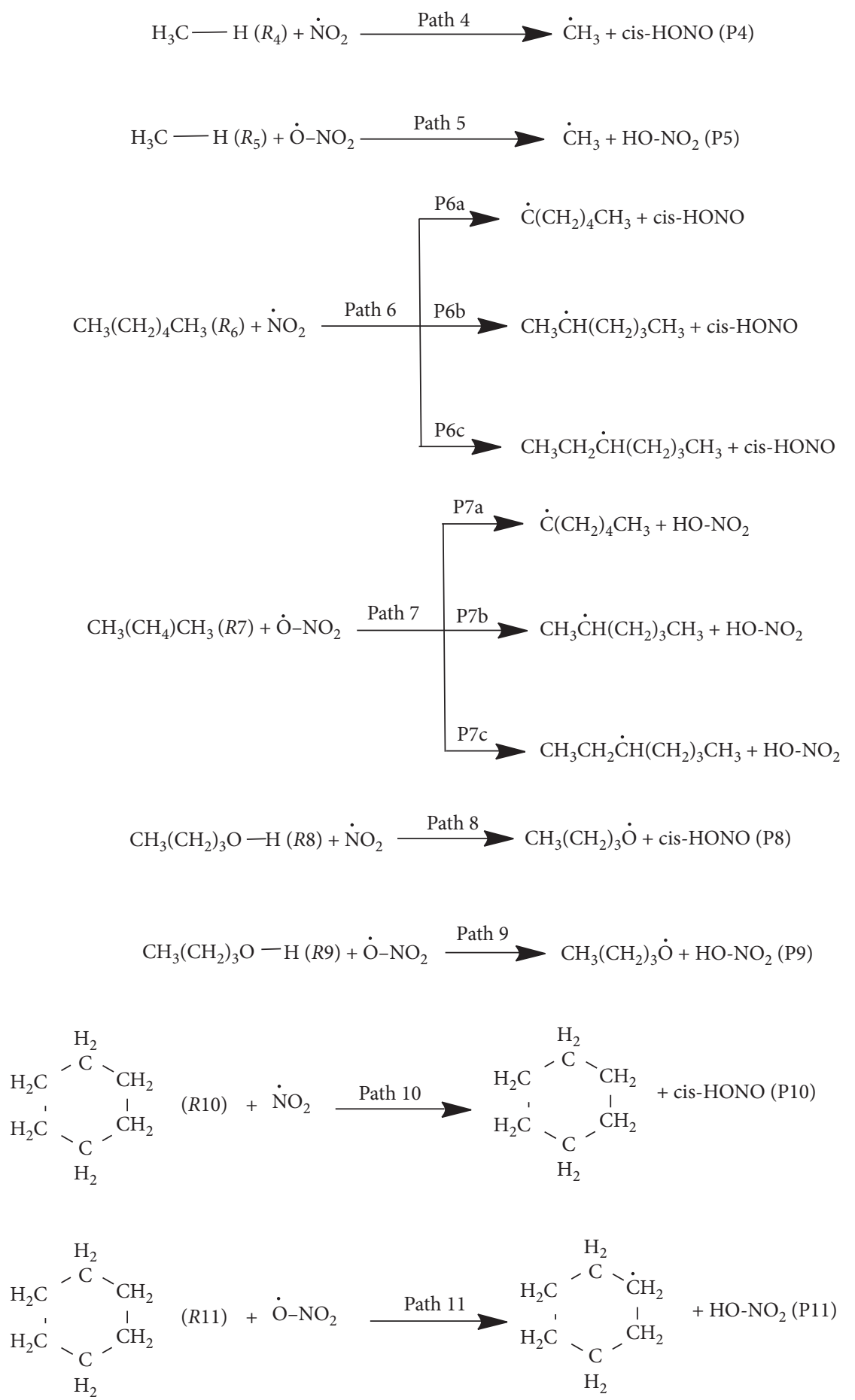

Figure 3: H-depletion by radicals.

Hence, Path $3 \longrightarrow$ Path 12 plays the main role for the formations of $\cdot \mathrm{NO}_{2}$ and $\cdot \mathrm{NO}_{3}$ radicals. This is consistent with the conclusion in Section 3.2. Comparing the rate constants of transition states $\mathbf{R N O}_{2}$ and $\mathbf{R} \mathbf{N O}_{3}$ in Figure 6(b), it can be seen that the rate constants differ greatly between them, and the attacking of alkanes or butanol by $\cdot \mathrm{NO}_{3}$ radical plays the dominant role, so we only discussed the rate constants of transition states $\mathbf{R N O}_{3}$. Here we only show the rate constants of transition state $c-\mathrm{C}_{6} \mathrm{H}_{11} \cdots \mathrm{H} \cdots \mathrm{NO}_{2}$ in Figure $6(\mathrm{~b})$ because we failed to get the transition state $c$ $\mathrm{C}_{6} \mathrm{H}_{11} \cdots \mathrm{H} \cdots \mathrm{NO}_{2}$ (TS11). The rate constants of TS11 are much higher than that of $c-\mathrm{C}_{6} \mathrm{H}_{11} \cdots \mathrm{H} \cdots \mathrm{NO}_{2}$ according to the rate constants trends. It could predict that the rate constants of TS11 are more than $1.22 \times 103 \mathrm{~mol}^{-1} \cdot \mathrm{L} \cdot \mathrm{s}^{-1}$ above $298 \mathrm{~K}$. As a result, the rate constants of these transition states increase as TS11, TS9, TS7c, TS7b, TS7a, and TS5. The product $c-\mathrm{C}_{6} \mathrm{H}_{11} \mathrm{NO}_{2}$ is the most competitive among the products. Because the rate constants of reactions $n$ - 
TABle 1: Activation free energies (in $\mathrm{kJ} / \mathrm{mol}$ ) of reactions between $\cdot \mathrm{NO}_{2}$ radical and alkanes or butanol in different pathways*

\begin{tabular}{lccr}
\hline Reactants & $\Delta G_{a}^{\neq}$ & $\Delta G_{b}^{\neq}$ & $\Delta G_{c}^{\neq}$ \\
\hline R4 & 172.94 & 151.92 & 165.91 \\
R6a & 161.77 & 140.93 & 144.20 \\
R6b & 148.81 & 128.72 & 127.67 \\
R6c & 150.20 & 129.26 & 130.14 \\
R8 & 147.08 & 129.92 & 141.41 \\
R10 & 60.01 & 37.83 & 39.46 \\
\hline
\end{tabular}

*Subscripts $a, b$, and $c$ in $\Delta G^{\neq}$denote the products of trans-HONO, cis-HONO, and $\mathrm{HNO}_{2}$, respectively.

TABLE 2: Activation energies, enthalpies, and free energies $\left(\Delta E^{\neq}\right.$, $\Delta H^{\neq}$, and $\Delta G^{*}$ in $\mathrm{kJ} / \mathrm{mol}$ ) of transition states at B3LYP/6-311++ $\mathrm{G}^{* *}$ level of theory in the gas phase.

\begin{tabular}{lccc}
\hline Transition states & $\Delta E^{\neq}$ & $\Delta H^{\ddagger}$ & $\Delta G^{\neq}$ \\
\hline TS4 & 124.77 & 122.34 & 151.92 \\
TS5 & 49.11 & 45.76 & 80.78 \\
TS6a & 103.07 & 102.93 & 140.93 \\
TS6b & 88.87 & 88.88 & 128.73 \\
TS6c & 89.55 & 89.66 & 129.26 \\
TS7a & 24.41 & 23.43 & 66.52 \\
TS7b & 10.38 & 9.07 & 54.67 \\
TS7c & 10.18 & 8.85 & 55.13 \\
TS8 & 90.61 & 89.45 & 129.92 \\
TS9 & -0.13 & -2.72 & 46.25 \\
TS10 & 1.65 & 6.40 & 37.83 \\
\hline
\end{tabular}

$$
\begin{aligned}
& \dot{\mathrm{C}} \mathrm{H}_{3}+\dot{\mathrm{NO}}_{2} \longrightarrow \mathrm{L} 1_{3} \mathrm{C}-\mathrm{NO}_{2} \\
& \dot{\mathrm{C}} \mathrm{H}_{2}\left(\mathrm{CH}_{2}\right)_{4} \mathrm{CH}_{3}-\dot{\mathrm{NO}} \underset{2}{\stackrel{\mathrm{L} 2 \mathrm{a}}{\longrightarrow}} \underset{\mathrm{CH}}{\mathrm{CH}_{3}\left(\mathrm{CH}_{2}\right)_{4} \mathrm{CH}_{2}} \stackrel{\text { I }}{\mathrm{NO}_{2}}
\end{aligned}
$$

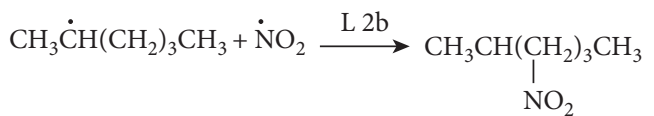

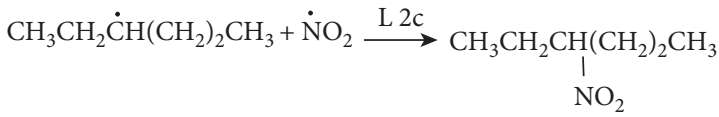

$$
\begin{aligned}
& \mathrm{CH}_{3}\left(\mathrm{CH}_{2}\right)_{3} \dot{\mathrm{O}}+\dot{\mathrm{NO}} \mathrm{O}_{2} \stackrel{\mathrm{L} 3}{\longrightarrow} \mathrm{CH}_{3}\left(\mathrm{CH}_{2}\right)_{3} \mathrm{O}-\mathrm{NO}_{2}
\end{aligned}
$$

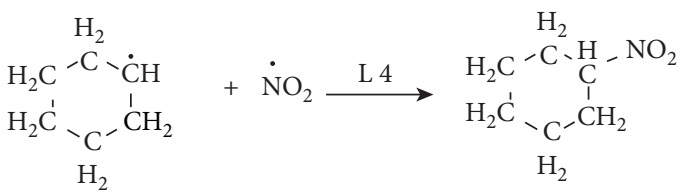

FIGURE 4: Formation of nitro compounds.

$\mathrm{C}_{6} \mathrm{H}_{14}+\cdot \mathrm{NO}_{3}$ are in the order of TS7c $\approx$ TS7b $>$ TS7a, the competitions of $\mathrm{CH}_{3} \mathrm{CH}\left(\mathrm{NO}_{2}\right)\left(\mathrm{CH}_{2}\right)_{3} \mathrm{CH}_{3}$ and $\mathrm{CH}_{3} \mathrm{CH}_{2} \mathrm{CH}\left(\mathrm{NO}_{2}\right)\left(\mathrm{CH}_{2}\right)_{2} \mathrm{CH}_{3}$ are close to each other, and both of them are less competitive than $c-\mathrm{C}_{6} \mathrm{H}_{11} \mathrm{NO}_{2}$ and $n$ $\mathrm{C}_{4} \mathrm{H}_{9} \mathrm{ONO}_{2}$. The product $\mathrm{CH}_{3}\left(\mathrm{CH}_{2}\right)_{5} \mathrm{NO}_{2}$ is only more competitive than $\mathrm{CH}_{3} \mathrm{NO}_{2}$, and the competition of $\mathrm{CH}_{3} \mathrm{NO}_{2}$
TABLE 3: Single point energies (in a.u.) of reactants and products of the whole reactions.

\begin{tabular}{lcc}
\hline \multirow{2}{*}{ Reactants or products } & \multicolumn{2}{c}{ Single point energies } \\
& Gas phase & TBP solvent \\
\hline $\mathrm{HNO}_{3}$ & -280.353196 & -280.358935 \\
$\mathrm{CH}_{4}$ & -40.406259 & -40.406399 \\
$n-\mathrm{C}_{6} \mathrm{H}_{14}$ & -236.470822 & -236.471107 \\
$n-\mathrm{C}_{4} \mathrm{H}_{9} \mathrm{OH}$ & -233.122168 & -233.126748 \\
$c-\mathrm{C}_{6} \mathrm{H}_{12}$ & -235.231335 & -235.231583 \\
$\mathrm{H}_{2} \mathrm{O}$ & -76.286534 & -76.293025 \\
$\mathrm{CH}_{3} \mathrm{NO}_{2}$ & -244.516677 & -244.523768 \\
$\mathrm{CH}_{3}\left(\mathrm{CH}_{2}\right)_{5} \mathrm{NO}_{2}$ & -440.590342 & -440.596577 \\
$\left.\mathrm{CH}_{3} \mathrm{CH}_{2} \mathrm{NO}_{2}\right)\left(\mathrm{CH}_{2}\right)_{3} \mathrm{CH}_{3}$ & -440.596533 & -440.602475 \\
$\mathrm{CH}_{3} \mathrm{CH}_{2} \mathrm{CH}_{2}\left(\mathrm{NO}_{2}\right)\left(\mathrm{CH}_{2}\right)_{2} \mathrm{CH}_{3}$ & -440.597671 & -440.603322 \\
$n-\mathrm{C}_{4} \mathrm{H}_{9} \mathrm{ONO}_{2}$ & -437.199490 & -437.204375 \\
$c-\mathrm{C}_{6} \mathrm{H}_{11} \mathrm{NO}_{2}$ & -439.392001 & -439.397493 \\
\hline & &
\end{tabular}

is negligible. The cyclic alkanes are the easiest to form nitro compound, followed by $n$-butanol, and $n$-alkanes are the least reactive to form the nitro compounds. That is consistent with the previous studies $[1,3,7,14]$. It can be also found that the long $n$-alkanes are easier to react with nitric acid to form the nitro compound than those of the short ones.

3.5. Relative Stabilities of Carbon-Centered Radicals and Reactivities of the Alkanes. For the carbon-centered radicals, their relative stabilities $(E)$ were obtained by using the expression [31]

$$
E=\Delta H_{0}+\sum \Delta H_{1}+\sum_{n-2}^{2} \frac{\Delta H_{n}}{\sqrt{2^{2.4}-2}},
$$

where $\Delta H$ is the energy contribution of a group to the relative stability. The number 0 represents the center $\mathrm{C}$-atom $\left(\mathbf{C}_{0}\right)$ of a radical that an $H$-atom is depleted. Number 1 is the $\mathrm{C}$-atom attached to the $\mathrm{C}_{0}$-atom directly, and the other numbers $n$ are the $n$ 'th $\mathrm{C}$-atom attached to the $\mathrm{C}_{0}$-atom. The energy contributions of the groups and relative stabilities of carbon-centered radicals are represented in Tables 5 and 6 .

As can be seen in Table 6, the relative stabilities of carbon-centered radicals are in the order of $\cdot \mathbf{R}_{6 \mathrm{~b}} \approx \cdot \mathbf{R}_{6 \mathrm{c}}<\cdot \mathbf{R}_{10}<\cdot \mathbf{R}_{6 \mathrm{a}}<\cdot \mathbf{R}_{4}$. In our calculations, the reactivities between alkanes and nitric acid decrease by the order of Path $10>$ Path $6 c>$ Path $6 b>$ Path $6 a>$ Path 4 . It is 

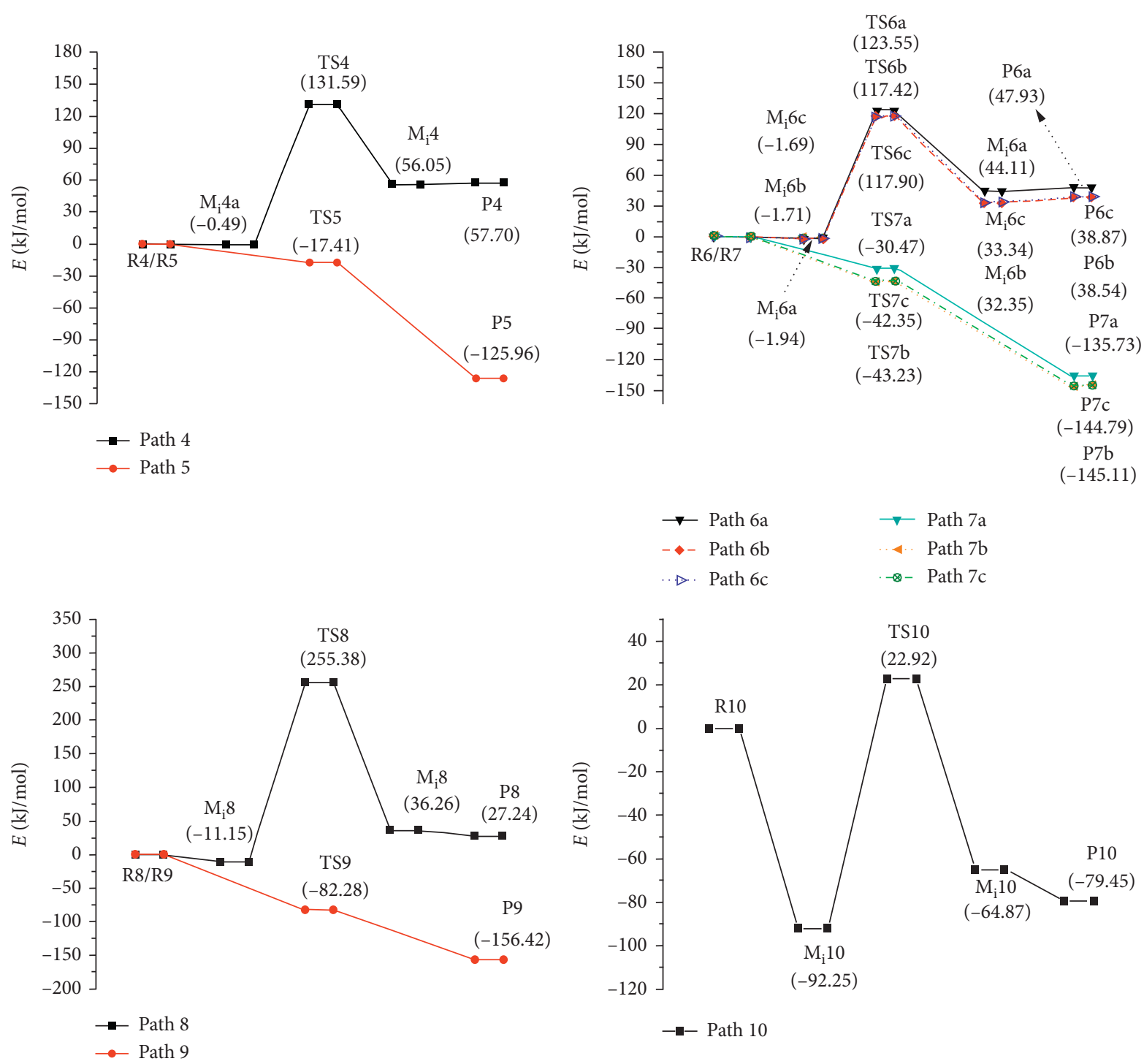

FIgURE 5: The relative energy along the reaction pathways at CCSD $(\mathrm{T}) / 6-311++\mathrm{G}^{* *} / / \mathrm{B} 3 \mathrm{LYP} / 6-311++\mathrm{G}^{* *}$ level.

TABLE 4: The rate constants $\mathbf{K}$ (TS1, TS2 in $\mathrm{K} \mathrm{s}^{-1}$ and the others in $\mathrm{mol}^{-1} \cdot \mathrm{L} \cdot \mathrm{s}^{-1}$ ) of reactions involved in the red oil system at $298 \mathrm{~K}$ in the gas phase or TBP solvent.

\begin{tabular}{lcc}
\hline \multirow{2}{*}{ Transition states } & \multicolumn{2}{c}{ Rate constants } \\
& Gas phase & TBP solvent \\
\hline TS1 & $1.07 \times 10^{-37}$ & $1.52 \times 10^{-35}$ \\
TS2 & $7.65 \times 10^{-30}$ & $4.19 \times 10^{-27}$ \\
TS3 & $9.28 \times 10^{-19}$ & $8.23 \times 10^{-15}$ \\
TS4 & $3.71 \times 10^{-16}$ & $2.43 \times 10^{-15}$ \\
TS5 & $1.08 \times 10^{-} 3$ & $6.46 \times 10^{-} 2$ \\
TS6a & $3.13 \times 10^{-14}$ & $3.13 \times 10^{-14}$ \\
TS6b & $6.58 \times 10^{-12}$ & $5.41 \times 10^{-11}$ \\
TS6c & $3.48 \times 10^{-12}$ & $2.87 \times 10^{-11}$ \\
TS7a & 0.34 & 9.08 \\
TS7b & 40.65 & $7.47 \times 10^{2}$ \\
TS7c & 33.77 & $1.35 \times 10^{3}$ \\
TS8 & $2.66 \times 10^{-12}$ & $1.32 \times 10^{-12}$ \\
TS9 & $1.21 \times 10^{3}$ & $1.70 \times 10^{4}$ \\
TS10 & $3.63 \times 10^{4}$ & $5.58 \times 10^{5}$ \\
\hline
\end{tabular}

worth noting that the competitions for the formation of $\mathrm{CH}_{3} \mathrm{CH} \quad\left(\mathrm{NO}_{2}\right)\left(\mathrm{CH}_{2}\right)_{3} \mathrm{CH}_{3}$ and $\mathrm{CH}_{3} \mathrm{CH}_{2} \mathrm{CH}\left(\mathrm{NO}_{2}\right)\left(\mathrm{CH}_{2}\right)_{2} \mathrm{CH}_{3}$ are similar. In general, the lower the relative stabilities of carbon-centered radicals, the more competitive the reactions between nitric acid and alkanes. The exception is the $\cdot \mathbf{R}_{10}$ radicals.

The relative stability of carbon-centered radical depends on the energy contributions of groups in the radical. The energy contributions of groups are related to their structures and relative positions to the $\mathrm{C}_{0}$-atom. As a result, for the chain and cyclic alkanes with the same number of $\mathrm{C}$-atoms, the relative stabilities of their corresponding carbon-centered radicals may differ slightly. However, the competitions of reactions depend on their activation energies. Comparing the activation energies for the formation of $\cdot \mathbf{R} 6$ and $\cdot \mathbf{R} 10$ radicals (Table 6), their activation energies differ greatly. Though there are small differences of relative stabilities between chain and cyclic carbon-centered radicals, there are still large differences in their reactivities. Therefore, the 


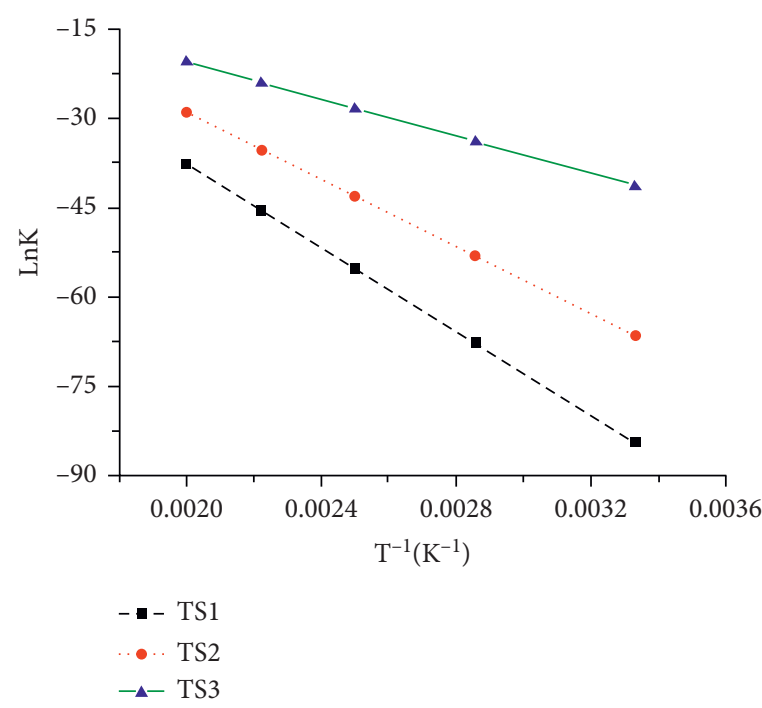

(a)

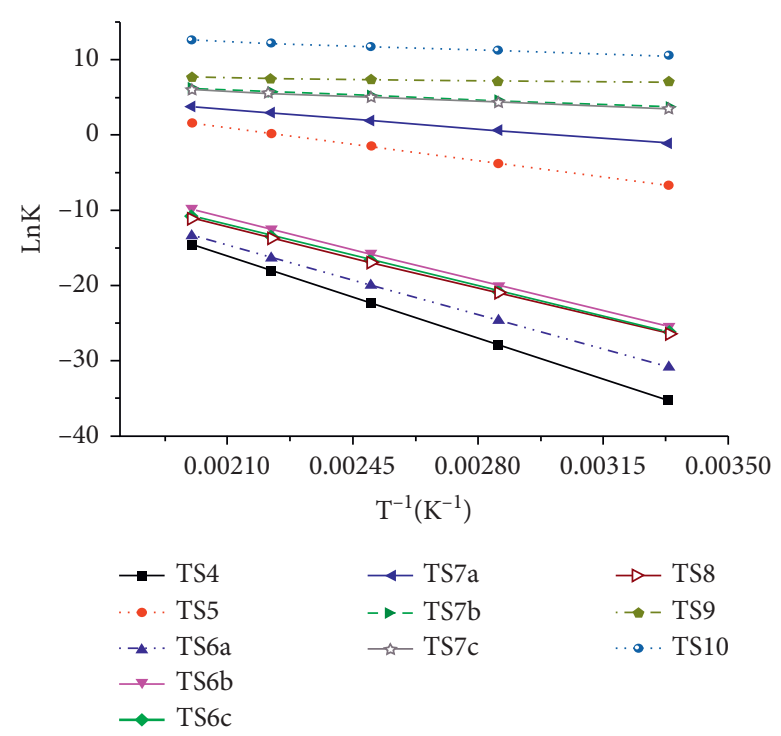

(b)

FIGURE 6: Rate constants of radical $\left(\cdot \mathrm{NO}_{2}\right.$ or $\left.\cdot \mathrm{NO}_{3}\right)$ formations (a) and reactions between radicals and alkanes or butanol (b) in gas phase at B3LYP/6-311++G** level.

TABLE 5: Energy contribution of a group to the relative stability of a radical in $\mathrm{kJ} / \mathrm{mol}[31]$.

\begin{tabular}{lc}
\hline Group & Energy contribution \\
\hline$\dot{\mathrm{C}} \mathrm{H}_{3}$ & 31.32 \\
$-\dot{\mathrm{C}}_{2}$ & 35.82 \\
$-\mathrm{CH}_{2}-$ & -4.93 \\
$-\dot{\mathrm{C}} \mathrm{H}^{-}$ & 37.45 \\
$\mathrm{CH}_{3}-$ & -10.20 \\
- & - \\
\hline
\end{tabular}

TABLE 6: Relative stabilities of carbon-centered radicals in $\mathrm{kJ} / \mathrm{mol}$.

\begin{tabular}{lcc}
\hline Carbon-centered radical & $\begin{array}{c}\text { Relative } \\
\text { stability }\end{array}$ & Activation energy \\
\hline$\dot{\mathrm{C}} \mathrm{H}_{3}\left(\cdot \mathbf{R}_{4}\right)$ & 31.32 & 124.77 \\
$\dot{\mathrm{C}} \mathrm{H}_{2}\left(\mathrm{CH}_{2}\right)_{4} \mathrm{CH}_{3}\left(\cdot \mathbf{R}_{6 \mathrm{a}}\right)$ & 23.84 & 103.07 \\
$\mathrm{CH}_{3} \dot{\mathrm{C}}\left(\mathrm{CH}_{2}\right)_{3} \mathrm{CH}_{3}\left(\cdot \mathbf{R}_{6 \mathrm{~b}}\right)$ & 16.17 & 88.87 \\
$\mathrm{CH}_{3} \mathrm{CH}_{2} \dot{\mathrm{C}} \mathrm{H}\left(\mathrm{CH}_{2}\right)_{2} \mathrm{CH}_{3}\left(\cdot \mathbf{R}_{6 \mathrm{c}}\right)$ & 16.28 & 89.55 \\
$\left(\cdot \mathbf{R}_{10}\right)$ & 19.20 & 1.65 \\
\hline
\end{tabular}

${ }^{*} \mathbf{R}$ represents carbon-centered radical.

reactivities of the same type of alkanes (either chain or cyclic alkanes) reacting with nitric acid can be speculated by comparing the relative stabilities of carbon-centered radicals. The lower the relative stabilities of carbon-centered radicals are, the more reactive the alkanes are. However, the reactivities of different type of alkanes cannot be determined by the relative stabilities of their corresponding radicals.

\section{Conclusion}

The reactions of nitric acid with some alkanes or butanol in red oil were studied by the quantum mechanics method. All the calculations were performed in TBP solvent and gas phase. The calculated geometrical structures of the transition states showed that the TBP solvent can speed up all the reactions, and the rate constants of reactions provide insight into the formations of red oil components. The reactions are in three steps. The nitrogen dioxide radicals and nitrogen trioxide radicals form firstly, and then these radicals initiate the depletion of $\mathrm{H}$-atom from alkanes or butanol; finally the generated radicals contact with each other and form the products. Though the energy barriers for the formations of $\cdot \mathrm{NO}_{2}$ and $\cdot \mathrm{NO}_{3}$ radicals are high, they could be overcome easily under $\gamma$-ray irradiation. The energy barriers of reactions $\mathbf{R}+\cdot \mathrm{NO}_{3}$ are much lower than those of reactions $\mathbf{R}+\cdot \mathrm{NO}_{2}$, so the reactions $\mathbf{R}+\cdot \mathrm{NO}_{3}$ are more competitive than the reactions $\mathrm{R}+\cdot \mathrm{NO}_{2}$. Among these products, $c-\mathrm{C}_{6} \mathrm{H}_{11} \mathrm{NO}_{2}$ is more competitive than the others and is the easiest to form. $\mathrm{CH}_{3} \mathrm{CH}\left(\mathrm{NO}_{2}\right)\left(\mathrm{CH}_{2}\right)_{3} \mathrm{CH}_{3}$ and $\mathrm{CH}_{3} \mathrm{CH}_{2} \mathrm{CH}\left(\mathrm{NO}_{2}\right)\left(\mathrm{CH}_{2}\right)_{2}$ $\mathrm{CH}_{3}$ are less competitive than $c-\mathrm{C}_{6} \mathrm{H}_{11} \mathrm{NO}_{2}$ and $\mathrm{CH}_{3}\left(\mathrm{CH}_{2}\right)_{3} \mathrm{ONO}_{2}$. Since the energy barriers and rate constants of the rate-limiting step for the formation of $\mathrm{CH}_{3} \mathrm{CH}\left(\mathrm{NO}_{2}\right)\left(\mathrm{CH}_{2}\right)_{3} \mathrm{CH}_{3}$ and $\mathrm{CH}_{3} \mathrm{CH}_{2} \mathrm{CH}\left(\mathrm{NO}_{2}\right)\left(\mathrm{CH}_{2}\right)_{2}$ $\mathrm{CH}_{3}$ are close to each other, the competition of them will depend on the actual experimental environment. Besides, the product $\mathrm{CH}_{3}\left(\mathrm{CH}_{2}\right)_{5} \mathrm{NO}_{2}$ is only more competitive than $\mathrm{CH}_{3} \mathrm{NO}_{2}$, and the competition of product $\mathrm{CH}_{3} \mathrm{NO}_{2}$ is negligible. The reactivities of the same type of alkanes reacting with nitric acid can be speculated by comparing the relative stabilities of carbon-centered radicals. The lower the relative stabilities of carbon-centered radicals are, the more reactive the alkanes are. However, the reactivities of different type of alkanes cannot be determined by the relative stabilities of their corresponding radicals. In general, long $n$-alkanes could be easier than 
the shorter ones to form nitrogen-containing organic materials that play roles in the "red oil" accidents $[3,7]$ as a uranium recycling medium.

\section{Data Availability}

The data used to support the findings of this study are available from the corresponding author upon request.

\section{Conflicts of Interest}

The authors declare that they have no conflicts of interest.

\section{Authors' Contributions}

Xue-Hai Ju conceptualized the study; Meng-Ke Tian and Shuang-Ling Tang were involved in data curation; ShuangLing Tang and Hong-Bin Tang were responsible for project administration; Meng-Ke Tian wrote the original draft; XueHai Ju wrote and reviewed the manuscript; and Shuang-Ling Tang and Hong-Bin Tang reviewed and edited the manuscript.

\section{Acknowledgments}

The authors thank the Joint Funding for Nuclear Technology Innovation Program of National Natural Science Foundation of China (No. U1867203) and Special Funding for Spent Nuclear Fuel Reprocesssing of China.

\section{References}

[1] P. L. Gorden, C. O’Dell, and J. G. Watkin, "Synthesis and energetic content of red oil," Journal of Hazardous Materials, vol. 39, no. 1, pp. 87-105, 1994.

[2] M. X. Xu, "Safety analysis on explosion of "red oils" in spent fuel reprocessing plants," Nuclear Safety, vol. 1, no. 1, pp. 22-27, 2001.

[3] T. G. Srinivasan and P. R. Vasudeva Rao, "Red oil excursions: a review," Separation Science and Technology, vol. 49, no. 15, pp. 2315-2329, 2014.

[4] N. J. James and G. T. Sheppard, "Red oil hazards in nuclear fuel reprocessing," Nuclear Engineering and Design, vol. 130, no. 1, pp. 59-69, 1991.

[5] S. Mishra, A. K. Soda, M. Sridhar, C. Mallika, N. K. Pandey, and U. K. Mudali, "Identification of diluent degradation products in radiolyzed PUREX solvent," Solvent Extraction and Ion Exchange, vol. 36, no. 1, pp. 54-65, 2018.

[6] O. K. Mallika, J. C. Mailen, and K. E. Dodson, "Purex diluent chemical degradation," Nuclear Technology, vol. 71, no. 2, pp. 417-425, 1985.

[7] B. Das, S. Kumar, P. Mondal, U. Kamachi Mudali, and R. Natarajan, "Synthesis and characterization of red-oil from tri iso-amyl phosphate/ $n$-dodecane/nitric acid mixtures at elevated temperature," Journal of Radioanalytical and Nuclear Chemistry, vol. 292, no. 3, pp. 1161-1171, 2012.

[8] P. L. Gordon, C. O'Dell, and J. G. Watkin, "Investigation of red oil decomposition by simulated Hanford tank wastes," Journal of Hazardous Materials, vol. 39, no. 1, pp. 69-86, 1994.

[9] K. Chandran, T. K. Sahoo, P. Muralidaran, V. Ganesan, and T. G. Srinivasan, "Calorimetric studies on the thermal decomposition of tri $n$-butyl phosphate-nitric acid systems," Journal of Thermal Analysis and Calorimetry, vol. 110, no. 2, pp. 879-890, 2012.

[10] V. N. Ganesan and G. S. Markov, "Incidents caused by red oil phenomena at semi-scale and industrial radiochemical units," Radiochemistry, vol. 45, no. 1, pp. 1-8, 2003.

[11] M. Epstein, H. K. Fauske, C. F. Askonas, M. A. Vial, and P. Paviet-Hartmann, "Thermal stability and safe venting of the tri-N-butyl phosphate-nitric acid-water ("Red oil”) system-III: predictions of thermal stability boundaries and required vent size," Nuclear Technology, vol. 163, no. 2, pp. 307-320, 2008.

[12] A. Wright and P. Paviet-Hartmann, "Review of physical and chemical properties of tributyl phosphate/diluent/nitric acid systems," Separation Science and Technology, vol. 45, no. 1213, pp. 1753-1762, 2010.

[13] V. S. Smitha, M. Surianarayanan, and H. Seshadri, N. V. Lakshman and A. B. Mandal, Reactive thermal hazards of tributyl phosphate with nitric acid," Industrial \& Engineering Chemistry Research, vol. 51, no. 21, pp. 7205-7210, 2012.

[14] V. S. Smitha, J. S. V. Kumar, M. Surianarayanan, H. Seshadri, and N. V. Lakshman, "Reactive chemical pathway of tributyl phosphate with nitric acid," Process Safety and Environmental Protection, vol. 116, pp. 677-684, 2018.

[15] B. J. Mincher, G. Modolo, and S. P. Mezyk, "Review article: the effects of radiation chemistry on solvent extraction: 1 . Conditions in acidic solution and a review of TBP radiolysis," Solvent Extraction and Ion Exchange, vol. 27, no. 1, pp. 1-25, 2009.

[16] M. V. Vladimirova and I. A. Kulikov, "Kinetics of radiolytic decomposition of tri-n-butylphosphate," Soviet Atomic Energy, vol. 60, no. 3, pp. 234-237, 1986.

[17] S. V. Sreekantan, S. Mahadevan, S. V. K. Jala, H. Seshadri, and A. B. Mandal, "Effects of diluents on the reaction hazards of tributyl phosphate with nitric acid," Organic Process Research \& Development, vol. 18, no. 12, pp. 1821-1827, 2014.

[18] V. S. Smitha, M. Surianarayanan, H. Seshadri, and A. B. Mandal, "Thermal behavior pattern of tributyl phosphate under adiabatic conditions," Journal of Thermal Analysis and Calorimetry, vol. 111, no. 1, pp. 849-856, 2013.

[19] E. V. Belova, G. F. Egorov, E. R. Nazin et al., "Thermochemical oxidation of components of extraction solutions and threshold conditions of thermal explosion: 4. Kinetics of reaction of TBP solutions in dodecane with nitric acid," Radiochemistry, vol. 43, no. 1, pp. 79-83, 2001.

[20] B. J. Mincher, S. P. Mezyk, and L. R. Martin, "A pulse radiolysis investigation of the reactions of tributyl phosphate with the radical products of aqueous nitric acid irradiation," The Journal of Physical Chemistry A, vol. 112, no. 28, pp. 6275-6280, 2008.

[21] G. F. Egorov, E. V. Belova, G. P. Tkhorzhnitskii, I. G. Tananaev, E. R. Nazin, and G. M. Zachinyaev, "Kinetics of thermochemical reaction of TBP solutions in HCBD with nitric acid in two-phase systems," Radiochemistry, vol. 50, no. 2, pp. 171-175, 2008.

[22] X. L. Wang, Z. Meng, and F. Gu, "Kinetics analysis of decomposing tributylphosphate with non-thermal plasma," Advanced Materials Research, vol. 875-877, pp. 940-946, 2014.

[23] B. Y. Zilberman and V. M. Chistyakov, " $\alpha$-Radiolysis of the tributyl phosphate-hydrocarbon diluent-nitric acid system," Radiochemistry, vol. 58, no. 2, pp. 188-202, 2016. 
[24] E. R. Nazin, G. M. Zachinyaev, E. V. Belova, G. P. Tananaev, and B. F. Myasoedov, "Exothermic processes in mixtures of TBP with nitric acid," Radiochemistry, vol. 59, no. 5, pp. 512-519, 2017.

[25] S. Kumar, P. K. Sinha, and U. Natarajan, "Thermal decomposition of red-oil/nitric acid mixtures in adiabatic conditions," Journal of Radioanalytical and Nuclear Chemistry, vol. 289, no. 2, pp. 545-549, 2011.

[26] S. V. Jala, S. V. Sreekantan, S. Mahadevan, H. Seshadri, and A. B. Mandal, "Influence of irradiation on the structure and thermo-kinetic behavior of tri-n-butyl phosphate," Journal of Thermal Analysis and Calorimetry, vol. 124, no. 3, pp. 1525$1534,2016$.

[27] S. C. Tripathi and A. Ramanujam, "Effect of radiation-induced physicochemical transformations on density and viscosity of $30 \%$ TBP-n-dodecane- $\mathrm{HNO}_{3}$ system," Separation Science and Technology, vol. 38, no. 10, pp. 2307-2326, 2003.

[28] T. Ando, Y. Fujimoto, and S. Morisaki, "Analysis of differential scanning calorimetric data for reactive chemicals," Journal of Hazardous Materials, vol. 28, no. 3, pp. 251-280, 1991.

[29] N. N. Wu, S. L. OuYang, and L. Li, "Theoretical study of $\mathrm{C}_{2} \mathrm{H}_{5}+\mathrm{NCO}$ reaction: mechanism and kinetics," Journal of Chemistry, vol. 2018, Article ID 036791, 8 pages, 2018.

[30] M. Lozynski, D. Rusinska-Roszak, and H.-G. Mack, "Hydrogen bonding and density functional calculations: the B3LYP approach as the shortest way to MP2 results," The Journal of Physical Chemistry A, vol. 102, no. 17, pp. 28992903, 1998.

[31] B. K. Carpenter, Research Method of Organic Reaction Mechanisms, pp. 133-236, Peking University Press, Beijing, China, First edition, 1991. 